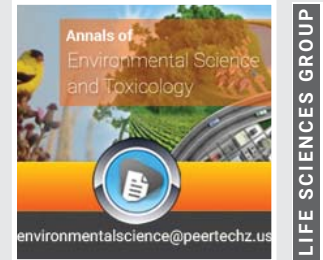

o

(8)

Environmental Science and Toxicology 2 gow
Research Article

\section{Evaluation of life cycle in the}

process of production and

management of PVC waste by LCA

method and prediction of toxicity

(TEQ) effect of dioxins using

\section{Artificial Neural Network method}

and nonlinear regression

\section{Mohammad Mahdi Shahsavar ${ }^{1}$, Nasim Ghadami², Mehran}

Akrami $^{3}$, Reza Aghlmand ${ }^{3}$ and Mohammad Gheibi ${ }^{3 *}$

'Department of Civil Engineering, Sajad University of Technology, Mashhad, Iran

${ }^{2}$ Department of Civil Engineering, Islamic Azad University, West branch of Tehran, Iran

${ }^{3}$ Department of Civil Engineering, Ferdowsi University of Mashhad, Iran
Received: 13 July, 2021

Accepted: 03 August, 2021

Published: 04 August, 2021

*Corresponding author: Mohammad Gheibi, Department of Civil Engineering, Ferdowsi University of Mashhad, Iran, Email: Mohammadgheibi@ymail.com Keywords: PVC; LCA; ANN; Gaussian model; Exponential model

https://www.peertechzpublications.com

Check for updates

\begin{abstract}
Today, using plastic tools and materials to meet executive and design needs is considered an integral part of industries such as the construction industry. Among these materials, PVC pipes in equipment and installations or UPVC windows could be mentioned. The missing link in the widespread use and utilization of this material is in the lack of attention to emissions from production and during waste management of the process. This study focuses on library studies to delineate the LCA cycle of air pollution in waste generation and management. At the end of the study, using the ANN artificial neural network method and the tested data, a logical relationship was found between the toxicity effect (TEQ) and the produced PCDD/F dioxins based on Gaussian and exponential models. The results of the obtained models have the ability to predict the toxicity effect with $60 \%-70 \%$ accuracy.
\end{abstract}

\section{Introduction}

The need of the construction industry for parameters such as lightness, flexibility, and speed in execution has increased the use of materials such as PVC. One of the widespread applications of PVC in the production of water pipes is for water supply facilities of buildings [1]. The Sustainable Development Perspective examines the production environmental aspects of this material. Human experience has shown that the manufacture and production of synthetic organic polymers always have severe environmental effects, of which PVC is no exception [2]. The results of Dr. Thornton's research at
Columbia University show that PVC production can have farreaching epidemiological effects as follows [3].

A. Phthalates in PVC are released in the factory space in the form of toxic dioxins. In some cases, its concentration reaches more than $1000 \mathrm{ppm}$.

B. Phthalates and dioxins released during production have effects such as asthma stimulation, bronchitis, pneumonia, irritating cough and runny eyes, and runny nose.

Khiz Bolia, et al. (1998) conducted a study on the effect of PVC pollution during production. It is worth mentioning that 
the focus of this research was on the production of PCB's dioxin [4]. ICI (1989) also conducted research on the production of pollutants such as PCDF's and PCDD'S. The results of this study showed that in order to prevent the production of the mentioned pollutants, all devices and tools should be calibrated, which is impossible to achieve [5]. A group of researchers at the University of Amsterdam in the Netherlands (1989) simulated the production of dioxins during EDC production. The results of this study showed that for every 100,000 tons of EDC production, 419 grams of dioxin is produced [6]. In another study, Krishnapatnam (2003) evaluated the effects of air pollution during the production of PVCs. This research has been done with the approach of investigating the effects of toxicity, greenhouse and the possibility of leakage [7]. Aliei, et al. (2013) investigated the pollutants from PVC production in a case study of Arvand Petrochemical. The study was conducted in the field of air and water; Finally, solutions for air and sewage purification were presented [8]. This research also intends to investigate the amount of air pollution during production and waste management using the LCA life cycle method and also to predict the toxicity effect (TEO) using modeling.

\section{Material and methods}

This research has been carried out in two parallel phases as follows. In the first part, by studying databases and reports, air pollution from PVC production was investigated in the LCA method. In the secondary part, the toxicity effect of PCDD/F dioxins was modeled using ANN artificial neural network system.

\section{Determining mass balance and air pollution during PVC production}

This part of the research, with library studies, calculated and classified the mass balance of input and output of production. Then the pollutants created during production and waste management were examined.

\section{Predicting the toxicity effect (TEQ) of PCDD/F dioxins}

As mentioned previously, one of the by-products when producing EDCs for VCM (PVC raw material) is dioxins. This part of the study also interpolated and extrapolated (with a limited radius) TEQ values for $\mathrm{PCDD} / \mathrm{F}$ concentrations by the ANN method. Modeling can predict the effects of hazardous dioxins as well as intelligent HSE control systems.

\section{Results}

According to studies conducted at the University of Oregan (Oregan uni.) In the United States, per kilogram of PVC production, $0.42 \mathrm{~g}$ of photochemical product, $0.142 \mathrm{~kg}$ of non-hazardous waste, $0.008 \mathrm{~kg}$ of hazardous waste, $0.62 \mathrm{~g}$ of phosphate production, $0.486 \mathrm{~g}$ of suspended particles, $5.3 \mathrm{~g}$ of sulfur dioxide with the potential to cause acid rain, $1.9 \mathrm{~kg}$ of sulfur dioxide with the effect of global warming and a total of 2056.826 g of pollutants are produced as described in Figure 1.

Analysis, review, and compliance of data reported by the University of Amsterdam [6], Oregon [9] and the report of
Malbasa, et al. on the DINA plant in the Czech Republic [10], show $1 \%-2 \%$ by weight of chlorine gas During chemical recycling PVC and $2 \%-5 \%$ by weight are released into space during waste generation as shown in Figure 2. It is clear that the chlorine emitted poses a serious threat to the ozone layer if left unchecked.

Theisen (1991) conducted a study on measuring the toxicity factors of TEQ produced by PCDD/F during PVC production which the results are presented in Table 1 [11-15].

In this study, using ANN artificial neural network analysis, the values of expressed errors and their trend were analyzed in Table 1 and then the desired data were interpolated. The results of ANN analysis are as described in Table 2 and Figure 3.

As shown in Table 2, a set of figures consisting of laboratory data (Theisen) and ANN (modeled) is obtained. The obtained data were modeled by curve fitting methods and functions were
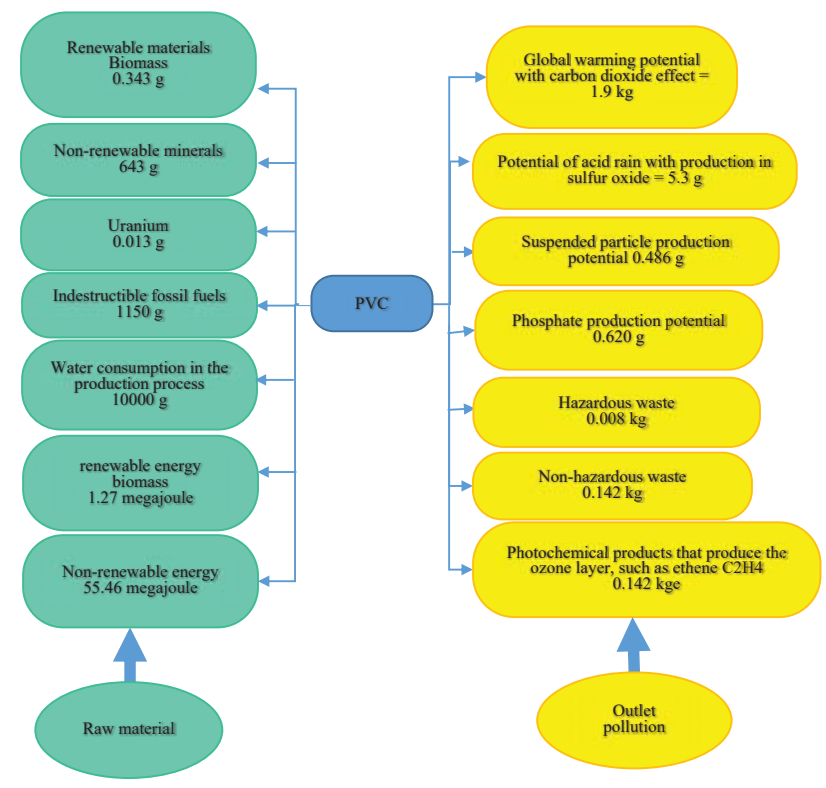

Figure 1: Mass balance of pollutant production per kg1 of PVC - Source - University of Oregon [9].

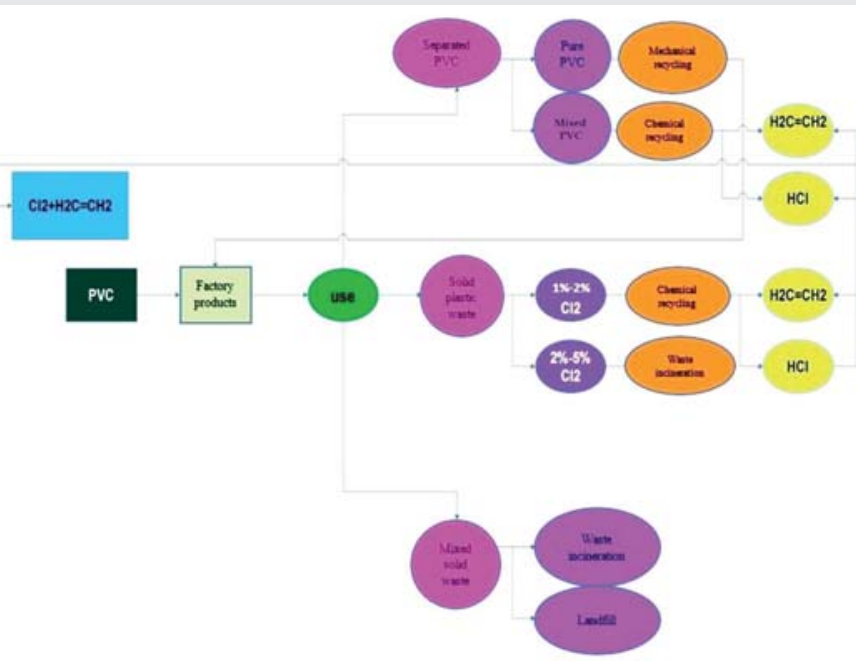

Figure 2: Chlorine production process during PVC waste management 
obtained by Gaussian and exponential distribution methods according to Tables 3 and Figures 4,5. Using the obtained functions, the toxicity effect (TEQ) can be calculated using the concentration of PCDD/Fs (ppt). The obtained functions can be more accurate by laboratory values and adding correction coefficients obtained from sensitivity analysis

\section{Conclusion}

Dioxin is a term with the formula $\mathrm{C}_{2} \mathrm{H}_{4} \mathrm{Cl}_{4} \mathrm{O} 2$ for a family of organic chlorinated compounds, some of which are highly toxic, even in small amounts. At the beginning of this study, due to the importance of pollution from PVC production and waste management, using the LCA method, the environmental effects during the production of the compound were evaluated. The results showed that 2056,826 grams of pollutants are generated per kilogram of PVC production. Also, about $5 \%$ of

Table 1: Toxicity effect of PCDD/F during PVC production.

\begin{tabular}{|c|c|c|}
\hline Type of PVC materials & $\begin{array}{c}\text { PCDD/F concentration } \\
(\mathbf{p p t})\end{array}$ & Toxic Compounds - TEQ \\
\hline PVC plastic & $244-2067$ & $3.2-42.2$ \\
\hline PVC flooring & $352-1847$ & $8.2-14.5$ \\
\hline PVC window frame & $7.5-969$ & $8.8-18.1$ \\
\hline PVC copper cable & $669-2670$ & $11.4-52.6$ \\
\hline Non-copper PVC cable & $416-843$ & $7.4-16.6$ \\
\hline PVC pipe & $158-954$ & $2.5-16.5$ \\
\hline $\begin{array}{c}\text { Chlorinated polyethylene } \\
\text { plastics }\end{array}$ & 840 & 10 \\
\hline Durable PVC plastics & $323-1096$ & $0.7-4.7$ \\
\hline
\end{tabular}

Table 2: Results of predicting the toxicity of TEQ from PCDD/F using ANN method. (actual values) Input $=$ PCDD, ppt (actual values) Output $=$ TEQ, equv (actual (actual values)

(actual values) $\begin{gathered}\text { Output }=\text { TEQ, equv (actual } \\ \text { values) }\end{gathered}$
(a)

\begin{tabular}{|c|c|}
\hline 1155.5 & 22.7 \\
\hline 1099 & 11.35 \\
\hline 488.25 & 13.45 \\
\hline 1684.5 & 32 \\
\hline 629.5 & 12 \\
\hline 556 & 9.5 \\
\hline 840 & 10 \\
\hline 790 & 2.7 \\
\hline
\end{tabular}

(Custom values) In put $=$ PCDD, $\mathrm{ppt}$

\begin{tabular}{|c|c|}
\hline 500 & 16.2869 \\
\hline 1000 & 28.0331 \\
\hline 950 & 20.6835 \\
\hline 900 & 8.833 \\
\hline 850 & 13.77 \\
\hline 800 & 20.762 \\
\hline 750 & 17.35 \\
\hline 700 & 3.02 \\
\hline 950 & 3.02 \\
\hline 450 & 8.5728 \\
\hline
\end{tabular}

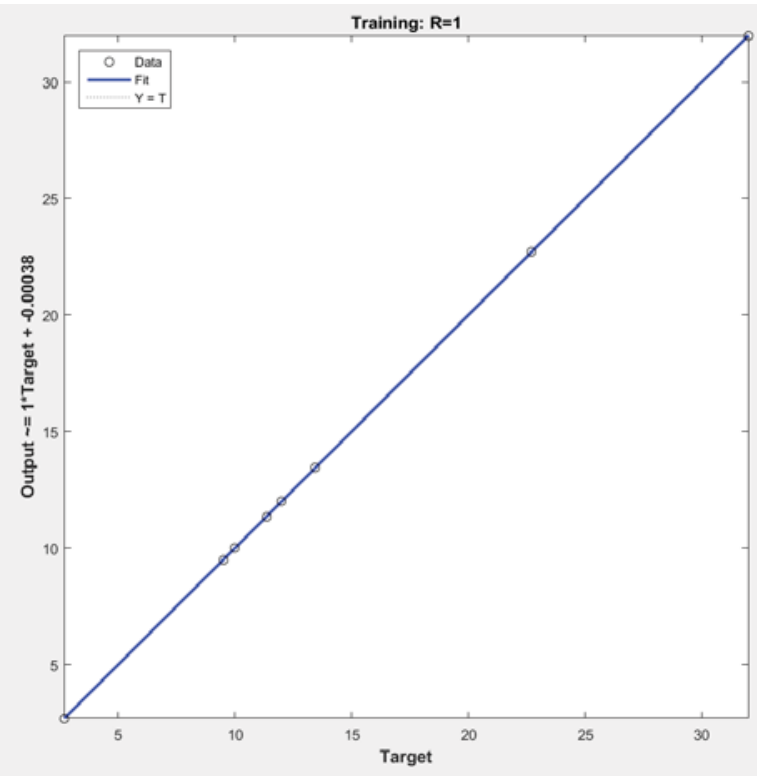

Figure 3: Fit the predicted data in the Matlab program.

Table 3: Description of Gaussian and exponential models for predicting TEQ.

\begin{tabular}{|c|c|c|c|}
\hline$R^{2}$ & Function constants & General shape of the function & Model \\
\hline $0 / 610$ & $A=9.639 * e^{81}$ & \multirow{5}{*}{$F(x)=A \exp (-(x-B) / C)^{2}$} & \multirow{5}{*}{ Gaussian } \\
\hline & $B=+3.582^{*} e^{5}$ & & \\
\hline & $C=+2.619 * e^{4}$ & & \\
\hline & $F(x)=T E Q$ & & \\
\hline & $X=P C D D / F(p p t)$ & & \\
\hline \multirow[t]{4}{*}{$0 / 7854$} & $A=+5.596$ & \multirow{4}{*}{$F(x)=A \exp (B x)$} & \multirow{4}{*}{ Exponential } \\
\hline & $B=+0.001041$ & & \\
\hline & $F(x)=T E Q$ & & \\
\hline & $X=P C D D / F(p p t)$ & & \\
\hline
\end{tabular}

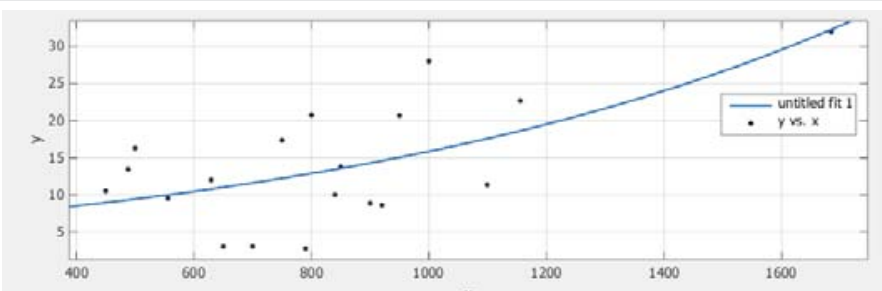

Figure 4: Fitting PCDD/F and TEQ values in Gaussian model.

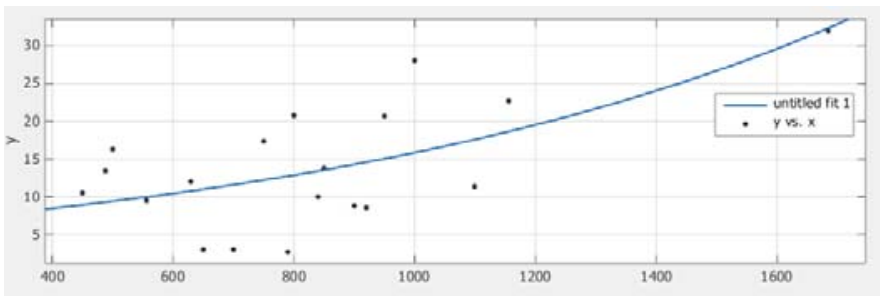

Figure 5: Fitting PCDD/F and TEQ values in the exponential model.

the weight of chlorine is released into the waste management process, which poses a serious threat to the ozone layer. The next step of this study was to predict the toxicity of TEQ dioxin compounds in PVC production. In this regard, Gaussian and exponential models were presented to predict the toxicity of PCDD/F (ppt) dioxins. We hope that the results of this research will help the development of dear Iran as much as possible. 


\section{References}

1. Wilkes CE, Summers JW, Daniels CA, Berard MT (2005) PVC handbook. Munich: Hanser 184. Link: https://bit.ly/3A6yS7S

2. ChemSystems (2008) PERP Program Report: Polyvinyl Chloride (PVC). San Francisco: Nexant Inc. https://bit.ly/2VaPwVm

3. Thornton J (2002) Environmental Impacts of Polyvinyl Chloride Building Materials. Washington D.C.: Healthy Building Network 110. Link: https://bit.ly/3igyPjU

4. Khizbullia F, Muslymova I, Khasanova I, Chernova L, Abdraschitov J (1998) Evaluation of polychlorinated dibenzodioxins and dibenzofurans emissions from vinylchloridemonomer production. Organohalogen Compounds 26 225-229

5. Lower Saxony Ministry of Environmental Affairs (1994) Data report and press release, dioxin data from $\mathrm{ICI}$ facility, Wilhelmshaven, Germany.

6. Evers E (1989) The formation of polychlorinated dibenzofurans and polychlorinated dibenzopdioxins and related compounds during oxyhydrochlorination of ethylene. Amsterdam: University of Amsterdam Department of Environmental and Toxicological Chemistry.

7. Chernaik M (2003) The Rapid Environmental Impact Assessment Reports for the Proposed PVC Project at Krishnapatnam, Andhra Pradesh. U.S. Environmental Law Alliance Worldwide.

8. Aliee N, Abbasi M (2013) An Evaluation of PVC Production Environmental Impact and Practical Solutions (In Persian), Third Environmental Planning and Management Conference; Iran: Tehran University.
9. Sara Tepfer for $\mathrm{CH} 114$ Green Product Design, University of Oregon, Department of Chemistry 2012.

10. Tomac V, Ćurković A, Malbaša N, Kovačić G, Štefančić B, et al. (2007) An Abstract for public review of an environmental impact study for the PVC production plant at the DINA PETROKEMIJA D.D. industrial complex at OMIŠALJ. ZAGREB. Link: https://bit.ly/2WJZeOB

11. Theisen J (1991) Untersuchung der moglichen umweltgefahrdung beim brand von kunststoffen (Investigation of possible environmental dangers caused by burning plastics) German Umweltbundesamt Report 104-09-222, Berlin, Germany.

12. Beiras $R$, Verdejo $E$, Campoy-López $P$, Vidal-Liñán $L$ (2021) Aquatic toxicity of chemically defined microplastics can be explained by functional additives. Journal of Hazardous Materials 406: 124338. Link: https://bit. ly/3rNRJBU

13. Sobhani Z, Fang C, Naidu R, Megharaj M (2021) Microplastics as a vector of toxic chemicals in soil: Enhanced uptake of perfluorooctane sulfonate and perfluorooctanoic acid by earthworms through sorption and reproductive toxicity. Environmental Technology \& Innovation 22: 101476. Link: https://bit. ly/3rSiR2p

14. Blass CR (1992) PVC as a biomedical polymer--plasticizer and stabilizer toxicity. Med Device Technol 3: 32-40. Link: https://bit.ly/3A84XMu

15. Wagoner JK (1983) Toxicity of vinyl chloride and poly (vinyl chloride): a critical review. Environ Health Perspect 52: 61-66. Link: https://bit.ly/2VudASQ

\section{Discover a bigger Impact and Visibility of your article publication with}

\section{Peertechz Publications}

Highlights

* Signatory publisher of ORCID

- Signatory Publisher of DORA (San Francisco Declaration on Research Assessment)

* Articles archived in worlds' renowned service providers such as Portico, CNKI, AGRIS, TDNet, Base (Bielefeld University Library), CrossRef, Scilit, J-Gate etc.

* Journals indexed in ICMJE, SHERPA/ROMEO, Google Scholar etc.

- OAI-PMH (Open Archives Initiative Protocol for Metadata Harvesting)

* Dedicated Editorial Board for every journal

* Accurate and rapid peer-review process

* Increased citations of published articles through promotions

* Reduced timeline for article publication

Submit your articles and experience a new surge in publication services (https://www.peertechz.com/submission).

Peertechz journals wishes everlasting success in your every endeavours.

Copyright: (c) 2021 Shahsavar MM, et al. This is an open-access article distributed under the terms of the Creative Commons Attribution License, which permits unrestricted use, distribution, and reproduction in any medium, provided the original author and source are credited.

Citation: Shahsavar MM, Ghadami N, Akrami M, Aghlmand R, Gheibi M (2021) Evaluation of life cycle in the process of production and management of PVC waste by LCA method and prediction of toxicity (TEQ) effect of dioxins using Artificial Neural Network method and nonlinear regression. Ann Environ Sci Toxicol 5(1): 099-0102. DOI: https://dx.doi.org/10.17352/aest.000045 